\title{
Other men's minds
}

\section{Kevin Connolly}

"PEOPLE come and go, but the creative sources of great historial events and the important ideas and deeds remain." This sentiment, expressed in the penultimate sentence of Alexander Romanovich Luria's short autobiography gives the key to the book. It is one of that small genre of intellectual autobiographies; it is fascinating because of the man and his work, and important because it spans almost the whole of Soviet psychology as it emerged from the deep and frowsty conservatism of tsarist Russia after the October revolution.

Luria was born in Kazan in 1902, into the Russian intelligentsia class. Arguably he was the best known Russian psychologist of his day, a prolific writer and an inveterate traveller. The cataclysmic changes of 1917 had a profound effect upon him: "The revolution freed us, especially the younger generation, to discuss new ideas, new philosophies and social systems." Although not aware of the real causes of the revolution Luria, in company with other young people, threw himself into the new movement because of the opportunities which it presented. In the opening chapter the liberation offered by the revolution in those early years comes across as a passionate, almost spiritual, excitement which served to fuel his intellectual endeavours.

Amidst the turmoil in Kazan University in the immediately post-revolutionary years Luria became absorbed with the then rather formless set of topics in the social and biological sciences which we now think of as psychology. After graduating in 1921 he began to investigate the effects of physical work on mental activity. His early studies on the role of verbal instructions on reaction time led to an enduring interest in the regulatory role of speech. He was also much interested at this time in psychoanalysis and had founded the Kazan Psychoanalytic Association.

In 1923 he moved to the Institute of Psychology in Moscow. The new Director, Kornilov, was engaged in eliminating all traces of subjective psychology and replacing it with objective methods - his "reactology". While appreciating the need for objective methods Luria avoided the sterility of this simple mechanistic scheme, his interest in psychoanalysis probably bolstered him in this. He designed a technique which he called the "combined motor method" to study the influence of

\begin{abstract}
The Making of Mind: A Personal Account of Soviet Psychology. By A.R. Luria. Edited by Michael Cole and Sheila Cole. Pp.234. (Harvard University Press: Cambridge, Massachusetts, and London, 1979.) $\$ 15$; £9.
\end{abstract}

emotions on voluntary behaviours. This early work, which was never published in Russian, shows clearly one of his trademarks - the application of objective methods to real life psychological problems.

In 1924 he met L.S. Vygotsky whom he describes quite simply as a genius. For ten years he worked closely with Vygotsky whose ideas plainly had a profound and enduring effect upon him. Vygotsky's 'cultural psychology' owed much to Marx's methods of analysis and to the intellectual climate released in Russia after the revolution. Inspired by Vygotsky's ideas Luria, Vygotsky and a small group of students set themselves the task of reconstructing psychology with man in his proper historical and cultural context. These ideas led Luria in the early 1930 s to make two expeditions to Uzbekistan in Central Asia. Here a traditional peasant society profoundly influenced by a conservative Islamic culture was in the process of being transformed by collectivisation, literacy campaigns and formal education. The purposes and methods, along with an outline of the findings obtained from the two expeditions are described. This brief account of the work on cultural differences in thinking done almost 50 years ago is one of the most interesting chapters in an absorbing book. It deals with work which is little known in the Soviet Union and even less in the west. Following these pioneering studies Luria turned to work on twins in an effort to disentangle nature and nurture as they shaped psychological processes. From the account provided one cannot help but be struck by the originality displayed in the work and by the way in which Vygotsky's theoretical framework is woven throughout it.

Luria was perhaps best known as one of the founding fathers of neuropsychology. In the late 1930s he completed his medical training in Moscow and set about becoming, as he puts it, "a practical neurologist"'. He made notable contributions to our understanding of the aphasias, once again informed by
Vygotsky's theory. When Russia entered the second world war in 1941 he was commissioned to organise a hospital for patients suffering brain injuries. The development of his ideas and methods of rehabilitation, especially in relation to speech, are simply and vividly described. The link between the war work and subsequent studies on the relationship between brain and behaviour, especially in connection with language function, is explored.

The final chapter in Luria's little memoire has the beguiling title, "Romantic Science". He distinguishes between classical science which is essentially reductive in nature, and romantic science which is concerned with the broader canvas of the whole person. In psychology the distinction and the corresponding dilemma have often been formulated in terms of the nomothetic versus idiographic approaches. Luria's work takes from both of these but in a period when the nomothetic approach is in the ascendency in western psychology his clear statement about the sources of ideas and about the importance of preserving the manifold richness of the subject, which he illustrates by his detailed studies of a man with an amazing memory and another man whose mind was shattered by a severe brain injury, provides a timely caution to us all.

In their introduction the editors provide a valuable historical context to Luria's psychological work. The final chapter is a sensitive and insightful essay by the editors in which they seek to give a picture of Luria the man. This is plainly difficult but the vicissitudes of his life are outlined and provide some explanation for the striking changes in direction which his work took, changes often brought about by political necessity. The two great influences on the development of Luria's psychological work were the revolution, which opened it, and Vygotsky whose ideas provided a connecting framework which ran throughout it. The atmosphere of the intellectual life which is revealed shows Luria to be a man possessed of boundless energy and insatiable curiosity - a great man. The book is quite simply a gem. Because of its simplicity and directness it reveals that most fascinating of things, another man's mind at work.

Kevin Connolly is Professor of Psychology at the University of Sheffield, UK. 